\title{
EL COMPLEJO ESCENARIO DE LA DISOLUCIÓN DEL PODER MILITAR EN LA ARGENTINA: LA AUTOAMNISTÍA DE 1983
}

\author{
MARINA FRANCO (IDAES-UNSAM/CONICET) \\ Programa de investigaciones sobre las Dictaduras del Cono Sur y Núcleo de Historia Reciente del \\ Instituto de Altos Estudios Sociales \\ Universidad Nacional de San Martín/CONICET \\ mfranco@unsam.edu.ar
}

\section{Resumen:}

Este trabajo analiza el proceso de gestación de la ley de autoamnistía militar de 1983, conocida como "Ley de Pacificación". A partir de documentación de la Junta Militar, recién hallada en 2013, se muestra en detalle como el principal obstáculo para la aprobación de la ley parece haber sido no la oposición civil sino los conflictos y diferencias intramilitares. Además, el examen de la documentación deja en evidencia que el gran riesgo que enfrentaban las Fuerzas Armadas hacia el final de la dictadura era el avance del poder judicial y el temor de que fueran los propios miembros de las fuerzas quienes comenzaran a denunciar lo hecho durante la represión. De esta manera, la ley de autoamnistía constituye un punto de acceso privilegiado para observar las dinámicas y tensiones en el proceso de disolución del poder militar en la Argentina.

\section{Palabras claves:}

Dictadura - Amnistía - Fuerzas Armadas - Ley de Pacificación

\begin{abstract}
:
This work analyzes the process of development of the 1983 military self-amnesty law, known as the "Pacification Law". It is clear from secret documentation of the military Junta, uncovered as recently as 2012, that the main obstacle to the passing of this law wasn't opposition from civil society, but rather conflicts and disagreements within the military itself. Furthermore, an examination of the documentation shows that the greatest threats that the military faced near the end of the dictatorship were the strengthening of judicial power and the possibility that members of the armed forces themselves might begin to denounce incidents that took place during the period of repression. The military self-amnesty law is a privileged point of access from which to observe the dynamics and tensions of the process of dissolution of military power in Argentina.
\end{abstract}

\section{Key words:}

Dictatorship - Amnesty - Armed Forces - Pacification Law 


\title{
EL COMPLEJO ESCENARIO DE LA DISOLUCIÓN DEL PODER MILITAR EN LA ARGENTINA: LA AUTOAMNISTÍA DE 1983
}

\author{
MARINA FRANCO (IDAES-UNSAM/CONICET)
}

mfranco@unsam.edu.ar

La llamada "Ley de pacificación" sancionada en septiembre de 1983 por la dictadura militar saliente estableció la amnistía para los crímenes cometidos por las fuerzas represivas y, dado su carácter "amplio", también incluyó la amnistía para los subversivos o terroristas cuyas acciones habían conducido -según los militares- a la lucha antisubversiva. ${ }^{1}$ Todos los países del Cono Sur sancionaron similares amnistías para esos delitos; Brasil y Chile lo hicieron aún durante el régimen dictatorial y Uruguay a comienzos del nuevo período democrático pero como resultado de negociaciones previas que condicionaron la transición. ${ }^{2}$ La Argentina no fue una excepción a ese proceso ni a esa perspectiva militar que consideró factible la impunidad por los delitos cometidos. La excepción argentina fue, en realidad, la dimensión del rechazo generalizado a esa autoamnistía que se produjo en la Argentina y la voluntad política del primer gobierno democrático y de las cámaras parlamentarias que la declararon nula en la primera sesión del congreso después de años de dictadura. ${ }^{3}$ A pesar de la importancia de ese hecho, hay que reconocer que esa voluntad política también fue posible por las condiciones de derrumbe con la que se produjo el fin del régimen militar en 1983. En otros términos, el fracaso y colapso del régimen militar en la Argentina fue una variable fundamental para que las fuerzas políticas entrantes -que se habían opuesto escasamente al régimen y menos aún a la lucha antisubversiva-

\footnotetext{
${ }^{1}$ A los efectos de facilitar la lectura, se ha tomado la decisión de suprimir comillas en términos nativos del lenguaje militar tales como subversión, terrorismo, etcétera. Esta decisión se sostiene en el hecho de que una gran mayoría de los términos que utilizamos tienen ese origen en los actores de época y por tanto un uso riguroso del recurso obligaría a colocar comillas en una gran diversidad de términos correspondientes a distintos actores. Por tanto, en estos casos las comillas en realidad están expresando una distancia ideológica que no considero necesario enfatizar con ese recurso, ya que mi lugar de enunciación es claro al respecto.

2 En Brasil, la amnistía data de 1979 (Ley 6.683) y fue el resultado de una amplísima movilización social por una amnistía "amplia e irrestricta" que permitiera la liberación de los presos y el retorno de los exiliados. El gobierno dictatorial de Joao Figueiredo aprobó finalmente una ley que amnistiaba también a los militares responsables por la represión y no incluía a los "terroristas" responsables por "delitos de sangre". Hasta el día de hoy el consenso social y político a favor de esta ley ha bloqueado todo proceso de justicia en ese país. En Chile, la Ley de Amnistía fue aprobada por el gobierno de Pinochet en 1978 liberando de responsabilidad criminal a todas las personas que cometieron crímenes o encubrieron crímenes cometidos entre el día del golpe militar, el 11 de septiembre de 1973, hasta el 10 de marzo de 1978, fecha en que se levantó el estado de sitio. En Uruguay, la amnistía, también llamada Ley de Pacificación Nacional (Ley 15.737), fue una de las primeras medidas del nuevo gobierno democrático de José María Sanguinetti, en marzo de 1985. Estaba destinada a la liberación de los presos políticos y estableció la amnistía de todos los delitos políticos, comunes y militares conexos. Sus efectos fueron completados con la clausura de los procesos judiciales en curso y de nuevas causas a través de la Ley de Caducidad de la Pretensión Punitiva del Estado (Ley 15.848), aprobada en diciembre de 1986.

${ }^{3}$ Ley 23.040, 22/12/1983.
} 
tuvieran un margen de maniobra importante para no acordar limitaciones explícitas a la nueva democracia ni condiciones de impunidad. ${ }^{4}$

Si la oposición civil a la ley ha sido muy recordada, un capítulo menos conocido de ese proceso fueron las enormes dificultades que tuvieron las Fuerzas Armadas para sancionar esa autoamnistía, que no parecen haber emanado tanto de esa oposición civil como de las resistencias dentro de las propias filas castrenses y de la preocupación por protegerse frente al nuevo escenario judicial y democrático. ${ }^{5}$

Según lo previsto por la Junta Militar, la ley, que ya venía siendo pensada desde los últimos meses de 1982, formaba parte de un paquete de disposiciones tendiente a facilitar el proceso de institucionalización. ${ }^{6}$ Por lo tanto, debía ser aprobada junto con el "Documento final sobre la guerra contra la subversión y el terrorismo", dado a conocer en abril de 1983; una segunda ley que legalizaba los mecanismos de represión del terrorismo y la subversión, que fue finalmente sancionada pocos días después de la autoamnistía, en septiembre, y la ley de convocatoria a elecciones aprobada en julio de ese año. ${ }^{7}$ Sin embargo, la oposición generalizada de los actores civiles $\mathrm{y}$, por sobre todo, las disidencias internas fueron tales que el proceso se postergó durante meses -entre reuniones, consultas y borradores inter e intrafuerzas- y sólo se promulgó en septiembre de 1983. ¿Qué podía oponerse tanto a una medida que sancionaba la impunidad para todos los miembros de una institución íntegramente implicada en la represión y firmemente cohesionada en torno a ello? ${ }^{8}$

\footnotetext{
${ }^{4}$ Sobre la noción de transición por colapso y sus efectos, véase O’Donnell, G.; Schmitter, Ph. y Whitehead, L., Transiciones desde un gobierno autoritario. América Latina, Buenos Aires, Paidós, 1988. Sobre la posición de los partidos políticos y su apoyo a la lucha antisubversiva, véase en extenso Yanuzzi, María de los Ángeles, Política y dictadura, Rosario, Fundación Ross, 1996 y Quiroga, Hugo, El tiempo del proceso. Conflictos y coincidencias entre políticos y militares, 1976-1983, Rosario, Homo Sapiens, 2004. Agradezco enfáticamente a los miembros del Núcleo de Historia Reciente del IDAES sus comentarios a este texto y la rica discusión colectiva sobre el problema de los partidos políticos y la amnistía en la Argentina.

${ }^{5}$ La ley de Pacificación y el proceso final de la dictadura ha sido escasamente estudiado y ambos suelen ser abordados con menor profundidad como la etapa de crisis final del régimen. Son muy pocos los autores que se detienen en la coyuntura de la ley y de las internas militares vinculadas a ella (véase Quiroga, Hugo, El tiempo del proceso..., op. cit.; Novaro, Marcos y Palermo, Vicente, La dictadura militar 1976-1983, Buenos Aires, Paidós, 2003.). En cualquier caso, la nueva documentación disponible permite renovar completamente nuestro conocimiento del tema.

${ }^{6}$ Acta 265, 23/6/1983, p. 1; Tomo 6, Actas de la Junta Militar (www.archivosabiertos.com). Todos los documentos de actas de la Junta Militar citados corresponden al mismo tomo y ubicación.

7 En el "Documento final...", hecho público el 29 de abril, las Fuerzas Armadas asumían "una cuota de responsabilidad" por lo actuado en la lucha subversiva y dejaban al juicio de Dios y de la historia los "errores" cometidos en el marco de "actos de servicio" en cumplimiento de mandatos del gobierno nacional. Por último daban por muertos a los desaparecidos y negaban tener cualquier otra información para dar.

La "ley de enjuiciamiento de actividades terroristas y subversivas" (Ley 22.928, 27/9/1983) tenía como objetivo garantizar la celeridad de procedimientos y castigo en los casos de delitos de subversión, dando amplio margen de maniobra a jueces federales y fuerzas de seguridad para actuar, y establecía que si bien los delitos subversivos se trataban en la justicia ordinaria (no se creaba un fuero especial), las Cámaras Federales de apelación juzgarían en instancia única, sin apelación (Anales de la Legislación Argentina, 43-D, 1983, p. 3837 y ss.). La ley fue duramente cuestionada por la oposición partidaria por sus procedimientos, no por sus principios de "contención de la subversión" (Diario Clarín, 28/9/1983). Una ley sustituta, basada en las garantías constitucionales de los inculpados, fue sancionada por el Congreso en 1984 como ley de "Protección del orden constitucional y de la vida democrática" (Ley 23.088, 9/8/1984).

La Ley 22.847 de convocatoria a elecciones generales de autoridades nacionales, provinciales y municipales fue promulgada el 13 de julio de 1983.

${ }^{8}$ Sobre la importancia de la cohesión ideológica en torno a la lucha antisubversiva en las Fuerzas Armadas, véase Canelo, Paula, El proceso en su laberinto. La interna militar de Videla a Bignone, Buenos Aires, Prometeo, 2008.
} 
Este artículo examina el proceso de gestación de la autoamnistía y las polémicas que suscitó dentro de las Fuerzas Armadas a partir del alcance público que esas diferencias adquirieron en los medios de la época y de documentos internos de las distintas armas, en especial, a partir del fondo documental hallado en octubre de 2013 en el edificio Cóndor de la Fuerza Aérea de la ciudad de Buenos Aires y desclasificado por la Secretaría de Derechos Humanos del Ministerio de Defensa. Estos documentos militares comprenden las Actas de cada una de las reuniones periódicas (en general semanales) de la Junta Militar a lo largo de 1983 y otros documentos internos de la Fuerza Aérea, todos de carácter secreto. ${ }^{9}$

\section{La Junta Militar frente a un escenario adverso}

Toda la documentación interna militar que hemos examinado consideraba como un dato de época el "desprestigio" de las Fuerzas Armadas en 1983 y el clima "desfavorable" al gobierno, al punto que afirmaba que se estaba intentando "polarizar" a la opinión pública en un "enfrentamiento civil-militar" y que cualquier intento de "revitalizar" la imagen de las Fuerzas Armadas no tendría muchas posibilidades. ${ }^{10}$ La principal fuerza de esa oposición provendría de la subversión ahora identificada con los organismos de derechos humanos y su accionar dentro y fuera de país. El poder ideológico que aún en 1983 la dictadura otorgaba a la subversión era tal que un informe secreto que establecía la urgencia de la ley indicaba que el discurso de los organismos -considerados "ooss", organizaciones subversivas- estaba penetrando entre las Fuerzas Armadas e incidiendo en la oposición militar a la amnistía. Según el informe, la importancia de esa acción subversiva contra la ley dejaba a la vista que la norma es "el único instrumento válido que se opondría" a los objetivos de esos grupos. ${ }^{11}$ Como prueba de ello, el informe incluía el detalle de las acciones de diversos organismos de derechos humanos dentro y fuera del país, de exiliados y de estados extranjeros contra la ley de amnistía. Entre ellos se anexaba una copia de una carta privada manuscrita de Nora Cortiñas, madre de Plaza de Mayo, fechada el 4 de julio, en la que ésta señalaba que en ese momento el principal foco de la acción de Madres era la ley de amnistía y relataba acciones de grupos de exiliados argentinos en Cataluña opuestos al proyecto de amnistía militar. ${ }^{12}$

Así como las organizaciones de derechos humanos eran percibidas como una amenaza real y con poder efectivo sobre las intenciones de las Fuerzas Armadas, no sucedía lo mismo con otros actores de la oposición civil. Significativamente, los partidos políticos -que por entonces integraban en su mayoría la Multipartidaria ${ }^{13}$, eran mencionados como actores a consultar pero

\footnotetext{
9 Las actas de las reuniones de la Junta Militar se encuentran todas en www.archivosabiertos.com.ar. Otros documentos están depositados en la Biblioteca de la Fuerza Aérea, Buenos Aires; todos de consulta pública y abierta. Este trabajo se realizó gracias a una primera clasificación y digitalización, y podría estar sometido a revisiones si surgiese nueva documentación en ese fondo u otros. Agradezco a Stella Segado y Alejandra Dandan el acceso a esos documentos.

${ }^{10}$ Anexo 1, p. 1, Acta 261, 19/5/1983.

11 “Secreto. Informe Asesoramiento Ley de Pacificación”, Carpeta Secretario General de la Fuerza Aérea, s/f, circa julio 1983 (Biblioteca de la Fuerza Aérea).

12 "Secreto. Informe Asesoramiento Ley de Pacificación”, Carpeta Secretario General de la Fuerza Aérea, s/fecha, circa julio 1983.

${ }^{13}$ La Multipartidaria Nacional, integrada por la Unión Cívica Radical (partido convocante), el Partido Demócrata Cristiano, el Intransigente, el Justicialista y el Movimiento de Integración y Desarrollo, se formó a mediados de 1981 con el objetivo de presionar a la Junta Militar para una pronta democratización. Sus alcances fueron limitados y desde 1983 la acción de los partidos se había individualizado nuevamente en función de la competencia electoral. En su diagnóstico de la situación argentina, la Multipartidaria exigía el retorno al estado de derecho en la misma medida en que acordaba con la condena a la "etapa de la subversión deshumanizada y violenta" que habían rechazado las Fuerzas Armada junto con el pueblo. A ello unían su crítica a "la represión que desconoció derechos humanos" y
} 
en ningún momento como obstáculo o límite real o efectivo a las intenciones militares. En agosto de 1983, cuando el proyecto estaba bastante avanzado y había pasado por sucesivas reformulaciones, los principales dirigentes partidarios fueron convocados a una reunión de consulta. Según consigna un informe militar, Raúl Alfonsín (Unión Cívica Radical) y Oscar Alende (Partido Intransigente) habrían rechazado la invitación e Ítalo Luder (Partido Justicialista) y De La Rúa (UCR) no habría respondido a ella. Frente a la consulta por la ley, el resto de los dirigentes -siempre según la documentación interna de la Junta- habría acordado en esa instancia con la "necesidad de su promulgación", aunque la mayoría habría manifestado una oposición "mediana" al proyecto. ${ }^{14} \mathrm{Al}$ respecto, muchos de los dirigentes convocados habrían señalado que el momento no era el "oportuno" y que su posición en un futuro parlamento democrático sería plantear el debate sobre la ley, pero no su aceptación o su rechazo a priori. La excepción a esta mayoría había sido la opinión de Alvaro Alsogaray quien habría manifestado su posición favorable a la medida. Entre los concurrentes, sólo Arturo Frondizi (Movimiento de Integración y Desarrollo), Carlos Alberto Contín (UCR) y Jesús Mira (Partido Comunista) habrían señalado que la principal impugnación al proyecto era su carácter de autoamnistía militar; mientras que Alsogaray y Ure habrían objetado, por el contrario, que la ley liberara a los subversivos. ${ }^{15}$

Esta información permite confirmar algo que aparece en el debate y las tomas de posición públicas de la época: la oposición ampliamente generalizada de los dirigentes partidarios a la ley. ${ }^{16}$ Sin embargo, el informe militar también muestra que ninguna posición -con la excepción de Alfonsín y Alende, que son quienes además rechazaron la invitación a la consulta militar- era del todo taxativa en contra (o al menos no lo fue en la situación presencial de la reunión), y la mayoría revela cierto compás de espera. El caso de Luder es más complejo y ambiguo de lo que habitualmente se recuerda cuando se lo contrapone a Alfonsín y se señala que -a diferencia del candidato radical- el peronista estuvo a favor de no anular la amnistía si asumía la presidencia. Si bien Luder declaró en julio que aunque "no le guste a la ciudadanía" los efectos jurídicos de la amnistía eran "irreversibles" por el principio de la ley penal más benigna ${ }^{17}$, posteriormente y en repetidas ocasiones manifestó una franca oposición a la ley, al señalar, por ejemplo, que no era admitible ni política ni jurídicamente ${ }^{18}$ y manifestó que la derogaría en caso de ser presidente. $^{19}$

reclamaban "una explicación" a los familiares por los miles de desaparecidos, concluyendo en la necesidad de prudencia, cese de la injusticia y esclarecimiento de "situaciones irregulares" y "reparación de errores cometidos". (La propuesta de la Multipartidaria, Buenos Aires, El Cid Editor, 1982, pp. 28-33.)

${ }^{14}$ En varios informes se señala la necesidad de consultar a los partidos, y la prensa también da cuenta de que hubo reuniones al respecto aunque con afirmaciones y negaciones confusas por parte de los políticos indicados. Por su parte, el informe militar en el cual se basa nuestro análisis se titula "Opiniones sobre la ley de pacificación" y es un cuadro de múltiples entradas que clasifica las opiniones de cada dirigente, incluyendo una graduación de su "oposición" a la ley como leve, mediana o intensa. El informe no permite saber si las posiciones que se consignan son el resultado de una reunión o de consultas informales o de las opiniones públicas de estos políticos. El hecho de que para quienes no aceptaron la invitación no se consigna ninguna opinión parece indicar que la consulta fue presencial y se trató de una reunión política entre gobierno y partidos. (Anexo A, Acta 269, 4/8/1983).

15 Anexo A, Acta 269, 4/8/1983.

16 Para una exposición general de las posiciones negativas, véanse revista Siete Días, 27/7/1983, Diario La voz. 31/8/1983, Diarios La Nación y Clarín, 4/8/1983 y 20, 21 y 23/8/1983, entre muchos otros. La iglesia estaba dividida por la cuestión y había opiniones discordantes, véanse Diarios La Nación y Clarín, 8/8/1983. Luego de varias consultas la Iglesia definió que no se pronunciaría sobre la ley de amnistía dejando el tema a la libre interpretación de los fieles (Diario Clarín, 11/8/1983). La oposición a la ley convocó incluso una importante manifestación con 35 mil asistentes el 19 de agosto (todos los diarios, 20/8/1983).

17 Diario Clarín, 2/8/1983. El principio jurídico de la ley penal más benigna que supone que al determinar una condena por un delito, si existen dos normas que fijen sanciones por los mismos hechos los jueces deben aplicar aquella que sea menos dañina para el acusado. Esto sería válido incluso si la ley era derogada. Véase más adelante en este trabajo.

${ }^{18}$ Diario La voz, 31/8/1983. 
De hecho, sabemos con certeza que no concurrió a la reunión convocada por la Junta y eso fue públicamente informado en la época. Sin embargo, para el peronismo había otra cuestión más en discusión. María Estela Martínez de Perón, ex presidenta derrocada, se encontraba judicialmente inhabilitada a perpetuidad para ejercer cargos públicos y funciones políticas por malversación de fondos en el caso de la "Cruzada de la Solidaridad", causa que ya se le había iniciado antes del golpe de Estado en 1976. Por ese delito había cumplido además 5 años de prisión. Durante los meses de discusión de la ley de amnistía, y en el marco de la reorganización de los partidos políticos y el comienzo de la campaña electoral, se consideró la posibilidad de un indulto que rehabilitase sus derechos políticos. Ese indulto se efectivizó el 9 de septiembre ${ }^{20}$ y aunque el tema no fue objeto de una presión muy significativa de parte del justicialismo -e Isabelita ya había manifestado que no volvería a la actividad política-, la Junta Militar consideró que el indulto era parte de las medidas de "acción psicológica" tendientes a limitar la oposición civil. ${ }^{21}$ Sin embargo, no tenemos evidencias de que la decisión, tomada días antes de la sanción de la ley de amnistía, haya modificado las posiciones del peronismo sobre el tema.

En todo caso, lo que interesa señalar es que aunque la dirigencia política partidaria -junto con juristas, intelectuales y algunos miembros de la Iglesia-, aparezca como un frente opositor, generalizado y amplio a la ley, para las Fuerzas Armadas no parecen haber representado interlocutores significativos sobre los que había que accionar o negociar porque su oposición pusiera en riesgo o fuera un límite real a los objetivos militares -como sí aparecen en esa situación los organismos de derechos humanos-. Esta lectura de las Fuerzas Armadas contribuye a pensar desde otro ángulo un dato complejo que aún resta evaluar adecuadamente: la escasa incidencia de la dirigencia partidaria como actor conjunto en el proceso de salida dictatorial en relación, específicamente, con las violaciones a los derechos humanos. También explica el hecho de que -como veremos- las Fuerzas Armadas no creyeron que la ley iba a ser finalmente anulada por esos mismos partidos, envueltos en el clima antidictatorial generalizado que caracterizó la asunción de Alfonsín en diciembre de $1983 .^{22}$

A pesar de la escasa incidencia real del actor humanitario y partidario sobre el proceso de gestación de la ley que parece desprenderse de la documentación, la ley se encontró con otros obstáculos cuya fuerza, seguramente, superó las expectativas de la Junta Militar. Así, las disidencias entre las distintas armas y jerarquías frente a los diversos proyectos de ley fueron una de las dificultades más difíciles de resolver. El primer anteproyecto fue dado a conocer a fines de mayo; en los meses siguientes hicieron públicos numerosos trascendidos sobre su contenido y sus cambios; en agosto se conoció un nuevo anteproyecto y el proyecto finalmente aprobado se

${ }^{19}$ Diario Clarín, 18/8/1983.

${ }^{20}$ Decreto $2330 / 83$.

${ }^{21}$ Equipo de Compatibilización Interfuerzas (ECI), Anexo A, p. 15-16, Acta 274, 8/9/1983. Según la terminología castrense, la acción psicológica es "un recurso permanente de la conducción que regula el empleo de métodos, procedimientos, técnicas y medios que influyen sobre el campo síquico de determinado público" (Ejército Argentino, RV-136-1. Terminología castrense de uso en las fuerzas terrestres, Buenos Aires, Instituto Geográfico Militar, 1968, p. 7). Es evidente entonces que la Junta Militar seguía utilizando conceptos propios de la doctrina de la guerra revolucionaria para organizar sus actos de gobierno y que la percepción en términos de acción psicológica supone que la guerra contra la subversión continuaba en el plano cultural. Agradezco a Esteban Pontoriero la referencia y el comentario sobre el tema.

22 Según un informe de la revista Somos, muchos políticos se expresaron públicamente en contra de la amnistía pero habrían dado su visto bueno a la Junta Militar porque consideraban que de otra manera la situación sería inmanejable para el nuevo gobierno (29/7/1983). Esta apreciación coincide con lo consignado sobre el informe militar y la opinión favorable a la "necesidad" de la ley para la mayoría de los políticos consultados. El punto innegable para evitar cualquier generalización es que esa opinión favorable excluye a los líderes presidenciables de la época. 
redactó en septiembre. ${ }^{23}$ En efecto, la búsqueda de un consenso interno en torno a los alcances judiciales y temporales de la amnistía y sobre el momento de su promulgación llevó varios meses, con marchas, contramarchas y negociaciones que fueron modificando el contenido original de la norma y dando origen a sucesivas versiones.

Tal como era público en la época, el Ejército era la fuerza más preocupada por la pronta sanción de una amnistía amplia y que tuviera validez para hechos sucedidos hasta la fecha de su promulgación. La prensa de la época no dudaba en señalar que la razón de ese interés era que el Ejército era el arma más comprometida e involucrada en la represión. ${ }^{24}$ Aunque, la Marina también estaba fuertemente involucrada en la masacre, con figuras de alta visibilidad como el Almirante Massera - por entonces acusado del asesinato del empresario Fernando Branca- se oponía a ella de manera institucional. El almirante Oscar Franco, máxima autoridad del arma y miembro de la Junta Militar, rechazaba la ley por "razones éticas, morales y jurídicas". Sostenía Franco que la norma sería interpretada como un intento de eludir la justicia por parte de las Fuerzas Armadas y que "la responsabilidad por las órdenes impartidas" "es exclusiva de las autoridades militares" y quienes las cumplieron "están exentos de toda responsabilidad". ${ }^{25}$ En realidad, por detrás de estos argumentos estaba sencillamente la reivindicación del núcleo ideológico de la lucha antisubversiva: para la Armada, quienes habían participado en esa guerra lo habían hecho cumpliendo órdenes y por tanto no había razón ni causa para amnistiarlos, ni menos para beneficiar a los subversivos con ella. ${ }^{26} \mathrm{La}$ oposición del Armada fue tan dura y categórica que días después de dar a conocer un nuevo anteproyecto de ley, a comienzos de agosto de 1983, la Junta Militar debió anunciar que la ley quedaba aplazada por tiempo indeterminado por falta de acuerdo intramilitar. ${ }^{27}$

La oposición interna también reunía a los sectores más duros del Ejército como el general Ramón Camps, el general retirado Luciano Benjamín Menéndez, ${ }^{28}$ el jefe de la Policía bonaerense, general Fernando Verplaetsen ${ }^{29}$ y sectores intermedios de oficiales y suboficiales. ${ }^{30}$ Todos ellos se oponían a la ley porque ponía en términos de igualdad a militares y subversivos. Un grupo intermedio del Ejército incluso publicó en el diario La Nueva Provincia, de Bahía Blanca, un documento señalando que la amnistía era un "acto inmoral" "que ningún hombre de honor puede, ni debe admitir, más cuando ha combatido en defensa de la patria", que "solo beneficiará a los terroristas" en tanto eran esas las causas abiertas y no las de los militares, de manera que estos últimos tendrían que "autodenunciarse para poder beneficiarse" de la ley; que ante los ojos de la ciudadanía se equiparaba a los militares que lucharon por la defensa de la patria y a los terroristas. ${ }^{31}$ Llegado ese punto del conflicto, en respuesta a las reacciones internas y días después del aplazamiento por tiempo indeterminado, el Jefe del Ejército, el General Nicolaides, envió un radiograma a todas las unidades de su arma informando la determinación de los altos mandos del Ejército de aprobar una "amnistía amplia y general" que "brindara protección jurídica a quienes lucharon contra la subversión”." ${ }^{2}$

${ }^{23}$ Cfr. Diario Clarín 27/5/1983; 15/7/1983, 4/8/1983. Según las Actas de la Junta hubo dos anteproyectos fechados el 18 de agosto (Acta 270,18/8/1983) y el 8 de septiembre (Acta 274, 8/9/1983), respectivamente.

${ }^{24}$ Revista Somos, 29/7/1983.

${ }^{25}$ Diario Clarín, 6/8/1983.

${ }^{26}$ Revista Siete Dias, 27/7/1983.

27 Diario La Prensa, 6/8/1983.

${ }^{28}$ Diario Clarín, 30/7/1983.

${ }^{29}$ Diario Clarin, 23/6/1983.

${ }^{30}$ Diario Clarín, 18/8/1983.

${ }^{31}$ Diario La Prensa, 12/8/1983.

32 Diario Clarín, 12/8/1983. Aunque no sea el objeto de este trabajo, es importante señalar que este argumento que rechazaba la ley por igualar a "fuerzas del orden" que actuaron bajo órdenes legales con terroristas y por liberar a los 
Según un informe interno del Partido Comunista, que no hemos podido confirmar con otras fuentes, pero que se presenta como el resumen de un documento escrito del Ejército fechado el 15 de agosto de 1983, el imperativo del Ejército por aprobar la ley era tal que el Jefe del Ejército, Teniente General Cristino Nicolaides estaba dispuesto a dar un golpe interno y expulsar a la Fuerza Aérea y la Marina de la Junta Militar sino se aprobaba la norma. ${ }^{33} \mathrm{Si}$ bien la fuente no es completamente confiable y es imposible su verificación por otra vía, el dato resulta coherente y atendible en virtud de la dimensión del conflicto interno que parecía haberse planteado en el mes de agosto.

Días después de que se anunciara la suspensión del proyecto de ley, autoridades del gobierno informaron que las Fuerzas Armadas estaban estudiando la posibilidad de que la amnistía alcanzara sólo militares para responder a la oposición interna de la Armada y de oficiales del Ejército que se oponían a ser igualados con los terroristas. ${ }^{34}$

Por su parte, el desacuerdo de la Fuerza Aérea pasaba por la cuestión de la "oportunidad política", ya que las autoridades del arma sostenían que el fin del régimen militar no era el momento y que la ley debía sancionarse después de las elecciones -ya previstas para el 30 de octubre de 1983-, e incluso insistían en que el tema debería concertarse con el próximo gobierno entrante. Con las mismas intenciones de garantizar la aceptabilidad de la ley sostenían que sus alcances debían llegar hasta el fin del gobierno de la tercera junta militar (junio 1982) o hasta la toma de posesión de los últimos comandantes en jefe de las tres armas (octubre de 1982) y no incluir a quienes estaban en ejercicio en ese momento para evitar que fuera considerada una autoamnistía. $^{35}$

A diferencia de la oposición de la Marina y el Ejército que nunca aparece explícitamente en la documentación militar analizada -pero puede leerse entre líneas como causantes de todas las formulaciones y reformulaciones que surgió el proyecto y que analizaremos a continuación-, las divergencias de la Fuerza Aérea se mantuvieron hasta el final y fueron explícitamente consignadas. Días antes de la promulgación de la ley, las distintas fuerzas aún seguían discutiendo cuál sería la fecha adecuada para aprobarla, con el desacuerdo de la Aeronáutica que ponía el acento en el "costo político" de la medida. ${ }^{36}$ El último documento de discusión intramilitar y de decisión final y formal sobre la ley sólo explicita la disidencia de la Aeronáutica pero no de otros sectores. Ello permitiría suponer que los cambios introducidos en relación con la subversión en el contenido de la norma habrían logrado alguna forma de consenso u aceptación de parte de la Marina -o que la escena política y judicial que analizaremos a continuación hizo modificar esas

segundos no era exclusivamente militar y aparece en diversos actores del arco conservador de la época: desde los editoriales de los diarios La Nación (24/9/1983) y La Prensa (29/7/1983) hasta algunos jueces (Diario La Nación, 29/9/1983) y políticos de derecha como el caso de Alsogaray, ya mencionado. Incluso, muchos de quienes se oponen a la ley por su carácter de autoamnistía primordialmente no dejan de mencionar el "error" de la amnistía de 1973 que liberó a los terroristas (véase por ejemplo las opiniones de Eduardo Aliverti y Magdalena Ruiz Guiñazú, en Revista Siete días, 27/7/1983).

${ }^{33}$ Informe sobre posiciones militares ante la Ley de Amnistía, p. 2. (Archivos del Partido Comunista).

${ }^{34}$ Diario Crónica, 20/8/1983.

35 Diarios Clarín, 6/8/1983; Crónica, 20/8/1983. Luego de la guerra de Malvinas, el general Galtieri renunció a la presidencia el 17 de junio, el cargo fue ocupado de manera interina por su ministro del Interior, el General Saint Jean hasta que el $1^{\circ}$ de julio el Ejército designó al general Bignone como presidente, en el medio de la fractura de la Junta militar y el retiro de la Armada y de la Fuerza Aérea que dejó al Ejército a cargo del Ejecutivo. Por su parte, Galtieri pasó a retiro el 18 de junio y fue nombrado al frente del Ejército el teniente general Cristino Nicolaides. En septiembre se reconstituyó la Junta con los comandantes de las tres armas. También pasaron a retiro sucesivamente los comandantes de las otras fuerzas y en octubre terminó la renovación de los integrantes de la Junta: el 17 de agosto pasó a retiro Basilio Lami Dozo y fue nombrado en su lugar el brigadier general Augusto Jorge Hughes por la Fuerza Aérea; el $1^{\circ}$ de octubre Rubén Oscar Franco reemplazó a Jorge Anaya en la Marina.

${ }^{36}$ ECI, Anexo A, Acta 274, 8/9/1983. 
posiciones-. En cualquier caso, y dado que las decisiones de la Junta no requerían unanimidad de las tres armas, la disidencia parcial de la Fuerza Aérea no impidió la promulgación de la ley el 23 septiembre de 1983.

\section{Los imperativos militares: la cohesión interna y el escenario judicial}

"Quiero, eso sí, reiterar una firme convicción. Estoy decidido a comprometer toda mi autoridad, todo mi prestigio, y hasta mi vida si fuera necesario para asegurar que cada uno de los hombres que participaron en esta gesta, tendrán el respaldo que corresponde a un combatiente que actuó en el marco institucional de su fuerza y en respuesta a una agresión llevada a cabo por un enemigo artero y solapado que operó en propio territorio nacional." ${ }^{37}$

Un informe militar secreto, sin fecha, pero posiblemente redactado en julio de 1983, cita estas palabras del Jefe del Ejército para mostrar la importancia de lo que estaba en juego con la aprobación de la ley de autoamnistía. Como vimos, para entonces, la ley llevaba varios meses de discusión y desacuerdos entre las distintas fuerzas y había sido motivo de informes, consultas y reuniones de la Junta y de los secretarios generales de cada arma para encontrar una solución consensuada. El informe en cuestión, cuyos autores precisos dentro del gobierno militar desconocemos, cierra la cita anterior con el siguiente comentario:

"El incumplimiento de lo citado presupondría el quebramiento de la palabra empeñada y su cumplimiento, sin la existencia de la ley de pacificación, daría lugar a un conflicto de poderes, con el consiguiente riesgo para la cohesión de las ffaa [sic] y la fractura del proceso de institucionalización., ${ }^{38}$

Por la misma época, otro informe militar solicitado por la Junta Militar indicaba que, hacia el interior de las Fuerzas Armadas, promulgar la ley lo antes posible "proporciona tranquilidad al personal" y "reduce la posibilidad de que se produzcan hechos fuera de control que puedan perturbar la evolución de la situación". ${ }^{39}$ Estos análisis sobre la propia institución militar nos ponen ante un factor importante que estaba en juego hacia el final del régimen: garantizar la cohesión y el orden dentro de las fuerzas en relación con las posibles consecuencias de la revisión civil y/o judicial de los crímenes. ${ }^{40}$

Sin embargo, además de la disciplina y el orden intrafuerza -que es un principio importante de la vida militar- la preocupación por la cohesión interna estaba vinculada a otro hecho de implicancias aún más graves: que fuera de las propias filas de las Fuerzas Armadas de donde surgieran denuncias sobre los crímenes cometidos y elementos de prueba para las acciones ante la justicia.

El riesgo era bien real y concreto. El 13 mayo de 1983, un comando de la policía bonaerense secuestró y asesinó a los dirigentes montoneros Osvaldo Cambiaso y Eduardo Pereira Rossi en un bar de Rosario y sus cuerpos, con marcas de tortura, aparecieron en la localidad de Lima (provincia de Buenos Aires). El caso, a cargo de juez de San Nicolás, Juan Carlos Marchetti, y en pleno proceso de apertura política, generó gravísimas repercusiones para el gobierno militar que justificó el salvaje asesinato alertando sobre los riesgos de un "rebrote subversivo" y del regreso

\footnotetext{
${ }^{37}$ CJE, GU Uspallata, "Secreto. Asesoramiento Ley de Pacificación”, Carpeta Secretario General de la Fuerza Aérea. ${ }^{38}$ CJE, GU Uspallata, "Secreto. Asesoramiento Ley de Pacificación”, Carpeta Secretario General de la Fuerza Aérea. ${ }^{39}$ ECI, Anexo A, p. 3, Acta 274, 8/9/1983.

${ }^{40} \mathrm{El}$ análisis no era en absoluto errado si consideramos los levantamientos posteriores de Semana Santa en 1987. Ellos muestran que, efectivamente, la disciplina interna no estaba asegurada mientras las jerarquías no pudieran garantizar a sus subordinados la protección por lo hecho bajo la lucha antisubversiva.
} 
de los Montoneros al país. El fantasma del "rebrote" fue además agitado para denunciar que estaba en riesgo el proceso de normalización institucional y el paso a un nuevo gobierno democrático. ${ }^{41}$ Para julio, la causa judicial había avanzado notablemente y los implicados eran tres jefes policiales de la provincia de Buenos Aires que habían actuado bajo órdenes militares. Entre ellos estaba el oficial principal Luis Patti. En ese contexto, y en reacción a la renuencia de la Fuerza Aérea a aprobar la ley de autoamnistía, Patti amenazó secretamente con dar "a conocer los aviones (matrículas), aeropuertos, destino, fechas y personal que trasladó delincuentes terroristas a disposición final." ${ }^{42}$ Como vimos, la oposición de la Fuerza Aérea estaba vinculada no al espíritu de la ley, sino a la oportunidad de su aprobación y una de las opciones era que la amnistía llegara hasta 1982, mientras que el Ejército quería extender su validez para hechos acaecidos hasta la fecha de aprobación de la ley. La diferencia entre una y otra fecha era la amnistía para Patti y los implicados en el caso Cambiaso-Pereira Rossi.

Pero el caso Patti no era el único. Por la misma época, se aceleró la causa judicial sobre la Triple A que estaba en manos del juez José Nicasio Dibur y había sido reabierta en abril a raíz de las declaraciones de un ex miembro de la policía Rodolfo Peregrino Fernández quien en marzo de 1983 había testimoniado ante la CADHU (Comisión Argentina de Derechos Humanos) en España y ante Naciones Unidas explicando con mapas y organigramas el funcionamiento y estructura de la represión clandestina e involucrando a numerosos miembros de las Fuerzas Armadas. ${ }^{43}$ De hecho, en el mes de julio las Fuerzas Armadas examinaron en detalle un listado probablemente proporcionado por el propio juez Dibur- con todo el personal militar y policial incriminado por Peregrino Fernández, y entre los cuales se contaban decenas de altos oficiales y la mayoría de las máximas autoridades de cada arma a lo largo del período dictatorial. ${ }^{44}$

Para entonces, esta misma preocupación por las denuncias de ex agentes represivos llevó a las Fuerzas Armadas a revisar un listado de militares detenidos en los penales de Magdalena y Caseros evaluando la posibilidad de que se transformaran en "potenciales agentes de denuncia". El listado de presos militares y algunos agentes policiales hallado enumera con claridad, en letra manuscrita, los argumentos a ofrecerles frente a las confesiones o denuncias sobre la represión que pudieran hacer:

"Todo el que habla se autoincrimina.

$\left.1^{\circ}\right)$ Encubrimiento por denuncia tardía.

$\left.2^{\circ}\right)$ Si los otros niegan queda solo como responsable.

$3^{\circ}$ ) Pueden ser indultados o conmutados sin necesidad de incluirlos en la amnistía." 45

A continuación, el listado evaluaba cada caso e indicaba si eran amnistiables o si su pena podía ser conmutada y en algunos casos se consignaba en letra manuscrita "agradecido". Estas

${ }^{41}$ Diarios La Vor, 29/5/1983; Clarín, 3/6/1983.

42 "Comisario Patty" [sic], documento secreto y confidencial, s/f, Carpeta Secretario General de la Fuerza Aérea. Disposición final fue el término utilizado para referirse al destino de muerte que esperaba a los detenidos que serían asesinados y desaparecidos (Reato, Ceferino, Disposición Final, Buenos Aires, Sudamericana, 2012). De acuerdo a la terminología castrense el concepto se refiere al: "acto de descargar existencias, documentos, efectos excedentes, obsoletos o sobrantes según las normas vigentes. La disposición final podrá cumplirse mediante la transferencia, donación, venta, abandono o destrucción" (Ejército Argentino, RV-136-1. Terminología castrense de uso en las fuerzas terrestres, Buenos Aires, Instituto Geográfico Militar, 1968, p. 135). Al parecer los militares tomaron un concepto previo y lo resignificaron en el marco de la lucha antisubversiva. Nuevamente agradezco a Esteban Pontoriero por las referencias y el comentario.

${ }^{43}$ Diario Clarin, 13/4/1983.

44 "Personas involucradas en la denuncia protocolizada del Inspector de la Policía Peregrino Fernández, Anexo 2, s/f, Carpeta Secretario General de la Fuerza Aérea".

45 "Detenidos en el penal de Magdalena y en la unidad carcelaria 16 (Caseros), potenciales Difusores de denuncias", s/f, Carpeta Secretario General de la Fuerza Aérea. 
evidencias, aunque son insuficientes para llegar a una interpretación segura, indican que estos presos pueden haber sido consultados bajo la preocupación de que hablaran si no eran amnistiados junto con el resto de los miembros de la fuerza. Volveremos sobre esta cuestión más adelante.

Como se desprende de los casos mencionados, en los últimos meses de la dictadura el poder judicial, que comenzaba a movilizarse adaptándose el nuevo clima de época antidictatorial, o al menos a seguir el curso de las causas según criterios legales y jurídicos menos constreñidos políticamente, se había transformado en un frente amenazante para las Fuerzas Armadas. A lo largo de 1983, las citaciones y procesamientos de militares se multiplicaron en otras causas resonantes. En junio, el juez Oscar Salvi procesó al almirante Emilio Massera por la desaparición en 1977 del empresario Fernando Branca y ordenó su prisión preventiva. ${ }^{46}$ Simultáneamente se aceleraba la causa de la Triple A y la de Cambiaso y Pereira Rossi con la prisión preventiva de los tres jefes policiales implicados. También Viola, Videla y Suárez Mason eran citados a declarar por Dibur en el caso del embajador Hidalgo Solá ${ }^{47}$ y Videla y Harguindeguy eran procesados por el mismo juez en la causa por la detención de Carlos Menem en $1980 .^{48}$ Hasta qué punto la activación de la justicia - de la cual daba cuenta la prensa como un fenómeno novedoso y amenazante para el poder militar- ${ }^{49}$ podía ser una preocupación importante lo muestran las amenazas de Patti exigiendo la aprobación de la ley, pero también lo muestran las conversaciones "extraoficiales" que el juez Dibur mantuvo con miembros de las Fuerzas Armadas. En esas instancias, según transcribe un informante militar, el magistrado habría dicho que podía:

“demorar las citaciones hasta no más allá del 10 ago [agosto]. A partir de dicha fecha estará obligado a citarlos, habiendo para muchos de ellos suficientes causas para luego de las indagatorias dictarles la prisión preventiva." ${ }^{, 50}$

En función de esas afirmaciones de Dibur, el documento militar concluía "La única solución de fondo es promulgar la ley de pacificación, ya". ${ }^{51}$ Por tanto, la justicia era una amenaza creciente para el poder militar, en general, y para la cohesión de las fuerzas en particular. Pero lo era en la misma medida en que todavía contaban con aliados dentro del escenario judicial dispuestos a colaborar para impedir la penalización de los crímenes represivos.

Esos aliados llegaban hasta la máxima jerarquía del ámbito judicial. Según el acta de reunión de la Junta Militar del 13 de julio, el presidente de la Corte Suprema, Adolfo Gabrielli, había examinado el anteproyecto de ley dando el visto bueno jurídico indicando que "es viable, no tiene vicios de inconstitucionalidad y en función de su generalidad gozaría de aceptabilidad jurídica". ${ }^{52}$ Llegado este punto, vale la pena recordar que Gabrielli, y todos los miembros de la Corte, habían sido designados por el gobierno de facto asumido en $1976 .{ }^{53}$ El propio Gabrielli en 1980 había señalado lo siguiente:

"El gobierno del Proceso de Reorganización Nacional ha respetado y respeta los derechos civiles de los individuos, con las únicas limitaciones propias del estado de sitio y de las

\footnotetext{
${ }^{46}$ Diario Clarin, 22/6/1983.

${ }^{47}$ Diario Clarín, 6/9/1983.

48 Diario Clarin, 15/7/1983.

49 Diario Clarín, 23 y 26/6/1983.

50 “Expresiones Juez Dibur”, “Secreto. Informe Asesoramiento Ley de Pacificación”, Carpeta Secretario General de la Fuerza Aérea, s/f.

51 “Expresiones Juez Dibur”, “Secreto. Informe Asesoramiento Ley de Pacificación”, Carpeta Secretario General de la Fuerza Aérea, s/f.

52 Acta 268, 14/7/1983, p. 2.

53 Groisman, Enrique I., La Corte Suprema de Justicia durante la dictadura (1976-1983), Buenos Aires, CISEA, 1987.
} 
circunstancias especiales creadas por el terrorismo y la subversión armada e ideológica, cuya erradicación constituye el propósito principal o factor determinante de las 'Bases para la intervención de las Fuerzas Armadas en el proceso nacional' (...) En el ejercicio de esas limitaciones, el estado ha actuado enmarcado por la legalidad dada por una serie de leyes que sería largo enumerar, pero acerca de cuya aplicación si ha habido desvíos, se ha hecho efectivo en plenitud el control jurisdiccional que el Poder Judicial ejerce de esos derechos o garantías de la libertad individual, y es necesario recalcar que el Poder Ejecutivo ha sido respetuoso tanto de la independencia del Poder Judicial como de sus pronunciamientos."

Estas consideraciones y todas las evidencias halladas nos remiten a la complejidad de las relaciones con el poder judicial en la coyuntura de la "Ley de Pacificación". Por entonces, un informe del Equipo de Compatibilización Interfuerzas -mecanismo de consulta entre las tres armas que se creaba para temas específicos cuando era necesario- reunido a fines de agosto señalaba que aún considerando cualquier pronunciamiento de la Corte Suprema (que implícitamente se considera como favorable a la ley), no era clara cuál sería la reacción de los distintos jueces y camaristas, pero:

"todo hace presumir que en muchos casos estarán influenciados por la acción sicológica emprendida por las asociaciones nacionales e internacionales sobre derechos humanos, como así también por las declaraciones de la Federación de Colegios de Abogados [...] y por su situación de jueces en comisión que hace inseguro su futuro y el de su familia, dado que aún no ha sido sancionada la reforma a la Ley de jubilaciones de magistrados del poder judicial [...] Esta influencia puede llevar a una abierta oposición o resistencia a la aplicación de la ley y en otros una actitud obstruccionista, evitando por todos los medios a su alcance tener que pronunciarse [...] No obstante ello, existirán magistrados que tendrán sumo interés en rápidos pronunciamientos favorables, por razones vinculadas a la ágil terminación de causas engorrosas [...] como así también por haber comprendido dentro de su esfera la lucha contra la subversión [...] En tal sentido se estima que será considerable el número de quienes están en tal situación...."55

El análisis dista de dar por sentada la posición judicial, y aunque concluye con una apreciación favorable de las posibilidades de la ley entre los magistrados, muestra que la escena judicial no estaba garantizada, era un espacio de riesgo y una amenaza para las Fuerzas Armadas salientes. Es importante tener en cuenta que así como el gobierno militar destituyó a los jueces de la Corte Suprema y tribunales superiores de las provincias y los sustituyó por otros favorables al nuevo régimen, para el resto de los magistrados se optó por ponerlos "en comisión" y, por tanto, sujetos a remoción o confirmación. Esta situación podía durar un tiempo considerable para los jueces y hacía que convivieran jueces confirmados que debían jurar acatar los objetivos del Proceso de Reorganización Nacional (PRN) y aquellos otros que podían ser removidos en cualquier momento. ${ }^{56}$ Como señala Sarrabayrouse, más allá del sector de empleados, funcionarios y magistrados que comulgaron y apoyaron activamente a la dictadura, hubo muchos que apoyaron el régimen desde el cumplimiento de sus tareas rutinarias sin que ello implicara una necesaria comunión con los ideales del régimen autoritario. ${ }^{57}$ Poco propensos a discutir con el poder de turno, este grupo mayoritario se abocaba a intentar cumplir sus funciones burocráticas adaptándose a las circunstancias. Esto fue así tanto para el momento de mayor represión durante

\footnotetext{
54 Cit. en Groisman, Enrique I., La Corte Suprema de Justicia..., op. cit., p. 42.

55 ECI, Anexo 2, p. 13, Acta 274, 8/9/1983.

${ }^{56}$ Groisman, Enrique I., La Corte Suprema de Justicia..., op. cit.

${ }^{57}$ Sarrabayrouse Oliveira, María José, Poder Judicial y dictadura. El caso de la morgue, Buenos Aires, CELS-Del Puerto, 2011, p. 243.
} 
la dictadura militar, como para el momento posterior a la guerra de Malvinas, cuando la situación comenzó a cambiar. ${ }^{58}$

Por lo tanto, si visto a la distancia "no puede hablarse de un poder [judicial] independiente durante la dictadura" y la conducta de los magistrados pudo ser sumisa o independiente según los casos, ${ }^{59}$ desde la percepción militar la situación judicial a la salida de la dictadura se había tornado incierta y habían crecido los márgenes de independencia. De hecho, para enfrentar este riesgo, en la citada reunión se fijó un plan de "acción psicológica" para hacer aceptable la ley y compensar su signo negativo. Entre las medidas de gobierno se incluía una ley de jubilación para los miembros del poder judicial -previendo especialmente el caso de aquellos que pudieran ser dejados cesantes en el futuro-.$^{60}$

\section{¿Amnistía o autoamnistía? El problema de los subversivos}

Los debates sobre la ley muestran el estado de urgencia militar de autoprotegerse y el carácter totalmente secundario y de reaseguro legal por el cual se incluyó en ella a la subversión. Recordemos aquí que al igual que en la Argentina, todas las amnistías del Cono Sur fueron "dobles" y "amplias" para ser aceptables jurídicamente. Sin embargo, como vimos, esa mera excusa que era la inclusión de los subversivos fue uno de los principales obstáculos para su aceptación por parte de las Fuerzas Armadas en la Argentina. Lo que parecía inaceptable para los jefes militares "duros" como el General Camps y la Armada, era para los partidarios de la ley uno de las principales garantías de que la norma no fuera jurídicamente cuestionada.

En efecto, una de las principales preocupaciones de la Junta Militar era la suerte que podía correr la ley bajo el nuevo régimen constitucional. Para evaluar esa variable, entre otras, el 18 de julio se conformó un nuevo ECI. En la reunión se analizaron las posibles acciones negativas del Congreso frente a la ley: derogación, nulidad o la exclusión de los "llamados crímenes atroces o de lesa humanidad" de los alcances de la amnistía. Frente al escenario de la derogación, el informe determinaba que aún si se derogase la ley ya habría generado "derechos adquiridos"; es decir, que actuaría el principio jurídico por el cual ante cualquier delito toda inculpado está protegido por la "ley penal más benigna" y que una vez que la ley le es aplicada genera derechos y sus efectos siguen vigentes aún si fuese luego derogada. De hecho, este argumento era compartido por muchos juristas y aparece en la prensa de la época como el problema más importante que generaría la ley de amnistía. Incluso quienes se oponían a ella señalaban que una vez aprobada la amnistía, el principio de que todo individuo está protegido por ley penal más benigna la hacía invulnerable. ${ }^{61}$

\footnotetext{
${ }^{58}$ Sarrabayrouse Oliveira, María José, Poder Judicial y dictadura..., op. cit.

${ }^{59}$ Groisman, Enrique I., La Corte Suprema de Justicia..., op. cit., p. 39.

${ }^{60} \mathrm{La}$ continuidad o no de los miembros del poder judicial bajo un nuevo gobierno democrático fue objeto de debate y preocupación en el seno del poder judicial en la época (Groisman, Enrique I., La Corte Suprema de Justicia..., op. cit.). En ese marco, la ley de jubilaciones aprobada el 17 de octubre de 1983 (Ley 18.464) preveía condiciones de retiro jubilatorio por cesantía ante la posibilidad de que el nuevo régimen democrático dejara cesantes a los magistrados que actuaron durante la dictadura. En cualquier caso, Alfonsín optó por evitar reemplazos masivos de funcionarios y renovó ámbitos claves como la Corte Suprema de Justicia y la Cámara Federal de Apelaciones en lo Criminal de Buenos Aires.

Las otras medidas consideradas como parte de la acción psicológica eran el indulto de rehabilitación política para María Estela Martínez de Perón, el levantamiento del estado de sitio y la ley de enjuiciamiento de actividades terroristas.

${ }^{61}$ Véase entre otros, la opinión de Luder ya citada e informe de Revista Somos, 29/7/83.
} 
En segundo lugar, frente al argumento de nulidad, señalaba el informe, no hay antecedentes de esa conducta parlamentaria frente a una ley de amnistía. Por otra parte, se consideraba que su carácter amplio (incluyendo a subversivos) dificultaba que se declarara una nulidad parcial. El carácter "bilateral", "amplio" o "general" fue considerado en su momento como la clave que garantizaría que la norma fuese aceptada pues no vulneraría el principio de igualdad ante la ley. Como veremos, ya en democracia, la nulidad de la ley fue establecida según otros criterios que trascendían esta cuestión.

Por último, frente a la posibilidad de que se excluyeran del alcance de la ley los "crímenes atroces", el documento establecía que no había antecedentes de esa figura en la legislación argentina y su inclusión obligaría a un debate político extenso e implicaría la creación de una norma ex-post-facto. En definitiva, las Fuerzas Armadas nunca consideraron como una posibilidad real el escenario de juzgamiento civil que se planteó en 1985.

Finalmente, a los efectos de obtener aceptación pública de la ley, el 31 de agosto la Junta Militar realizó una nueva reunión de compatibilización interfuerzas en la cual se planteó la necesidad de una intensa "acción sicológica" (sic) frente a la opinión pública adversa. Entre las cuestiones a difundir por su incidencia favorable se incluía mostrar que: la ley era "moral" (por ser Constitucional); no incluía delitos económicos; los condenados o residentes en el exterior no estaban incluidos en la amnistía y, finalmente, que "no es una autoamnistía". ${ }^{62}$ Esta enumeración suponía que la exclusión de los condenados y de quienes estuvieran en el exterior daría legitimidad social a la nueva norma. Es decir, suponía consenso antisubversivo en la opinión pública.

Esto nos lleva al problema de las exclusiones de la ley. El texto final incluía un artículo general y tres artículos restrictivos que indicaban los grupos no alcanzados por la amnistía:

"Art. 2: Los miembros de las asociaciones ilícitas terroristas o subversivas que, a la fecha de la promulgación de los beneficios de esta ley no se encontraren residiendo legal y manifiestamente en el territorio de la nación argentina o en los lugares sometidos a su jurisdicción o que por sus conductas hayan demostrado el propósito de continuar vinculados con dichas asociaciones.

Art. 3: Quedan también excluidas las condenas firmes dictadas por los delitos y hechos de naturaleza penal referidos en el art. $1^{\circ}$, sin perjuicio de las facultades que, de conformidad con el inciso $6^{\circ}$ del Artículo 86 de la Constitución Nacional, el Poder Ejecutivo Nacional puede ejercer en materia e indulto o conmutación de penas impuestas por dichas condenas, para complementar el propósito de pacificación de esta ley.

Art. 4: No están comprendidos en los beneficios de esta ley, los delitos de subversión económica tipificados en los artículos 6, 7, 8, y 9 de la Ley 20.840." ${ }^{\text {63 }}$

Estas restricciones fueron sumamente discutidas y, de hecho, las exclusiones de los dos primeros artículos no estaban consideradas en las primeras versiones de los proyectos que se dieron a conocer públicamente hasta agosto. ${ }^{64}$

En lo que se refiere a la restricción para los subversivos residentes en el exterior (art. 2), la medida estaba vinculada al inminente regreso de dirigentes políticos -en particular de

\footnotetext{
${ }^{62}$ ECI, Anexo A, p. 15-16, Acta 274, 8/9/1983.

63 Proyecto final de Ley, Anexo B, p. 2, 31/8 al 2/9/1983, Acta 274, 8/9/1983, resaltado mío. La Ley 20.840 (28/9/1974) era la ley de seguridad aprobada durante el último gobierno peronista que, junto con el Estado de sitio, sirvió de marco legal para la represión generalizada de activistas políticos antes del golpe de Estado de 1976.

${ }^{64}$ No obstante, hemos encontrado algunos comentarios previos de que la ley no incluiría a los condenados, pero las afirmaciones más reiteradas de todas las primeras versiones del proyecto los incluían.
} 
Montoneros- que podían querer incorporarse al proceso electoral dentro del peronismo o generar conflictos partidarios, según las autoridades militares, en especial Mario Firmenich. ${ }^{65}$ Aunque la posibilidad de regreso de esos dirigentes no parecía ser bien recibida por nadie, es poco probable que la decisión fuera para satisfacer a la opinión pública civil. ${ }^{66}$ Aunque no tenemos información explícita de qué llevó a excluir a los residentes en el exterior, los documentos muestran el proceso de flexibilización y búsqueda de alternativas restrictivas a lo largo de todo el mes de agosto - recordemos que fue el momento más álgido del conflicto interfuerzas- para limitar los alcances de la amnistía sobre "la subversión". Todo parece sugerir que la búsqueda de esas restricciones estuvo vinculada a responder a las objeciones internas según las cuales la norma beneficiaba a los subversivos y los igualaba con los que habían luchado leal y legalmente para salvar al país.

Por su parte, la no inclusión de los condenados con sentencia firme -militares y terroristas (artículo 3) - no estaba considerada en las primeras versiones de los proyectos y fue también una inclusión tardía de mediados de agosto. ${ }^{67}$ Una reunión de la Junta de comienzos de ese mes compara la cantidad de subversivos y militares condenados que serían liberados por la amnistía y establece que entre los primeros había 350 en la cárcel y entre los segundos solo 150. Sin embargo, al analizar en detalle, el informe muestra que de los 350 "subversivos", hay 310 que de no ser liberados por la amnistía estarían ya en condiciones de obtener su libertad condicional "ahora" (agosto de 1983) o en enero de 1984. Por lo tanto, si se aprobaba la amnistía para los subversivos condenados, sólo 40 serían realmente beneficiados y, al contrario, de no hacerse la ley, seguramente serían liberados por una amnistía del nuevo gobierno. En cambio, muestra el informe, el conjunto completo de los 150 militares condenados serían beneficiados por la amnistía en términos efectivos. ${ }^{68} \mathrm{~A}$ pesar de este esquema que minimiza los efectos de una amnistía para los subversivos condenados, esta opción finalmente fue excluida de la ley.

En el mismo informe se indicaba que entre los subversivos no condenados había 163 detenidos a disposición del PEN y 890 que estarían en el exterior habiendo salido por el derecho de opción. ${ }^{69}$ Ante este cuadro general de la situación, el informe planteaba explícitamente buscar mecanismos que limitaran la liberación de los subversivos beneficiados por la ley, entre ellas, por ejemplo que los subversivos fueran excarcelados pero puestos a disposición del Poder Ejecutivo. Como sabemos, finalmente, la decisión fue excluir a los condenados y los residentes en el exterior, los dos grupos mayoritarios con 350 y 890 subversivos respectivamente.

Ahora bien, luego de la decisión de no incluir a los condenados con sentencia firme en la amnistía se agregó una variable más que pasó al texto final de la ley: esas condenas podían ser revisadas por la autoridad presidencial para recibir un indulto o para ser conmutada la pena (art. 3). ${ }^{70}$ Esas decisiones seguramente se explican por el temor a las denuncias de los propios miembros de la fuerza ya que, como señalaba un documento militar, "es factible que por reacción" se produzcan

${ }^{65}$ Diarios Clarin, 3/6/1983; 15/7/1983; La voz, 29/5/1983. En cualquier caso, debe considerarse que Firmenich no tenía causa pendiente en el país y por tanto no estaba alcanzado por la amnistía (Revista Somos, 29/7/1983). De todas formas, si las disposiciones de la ley hubieran incluido a las personas en el exterior lo hubieran protegido de que se le abriera cualquier causa o investigación a su regreso.

${ }^{66}$ Después de las elecciones, Mario Firmenich anunció sus intenciones de volver al país en una carta abierta enviada a partidos y organismos de derechos humanos. Su iniciativa fue recibida con un rechazo bastante amplio que excedió a los actores prodictatoriales (Diario Clarín, varios, diciembre de 1983) y muestra lo adecuado de la percepción militar sobre las ventajas públicas de excluir a las residentes en el exterior.

${ }^{67}$ ECI, Proyecto de Ley, Anexo C, p. 1, Acta 270, 18/8/1983.

${ }^{68}$ Anexo C, Acta 269, 4/8/1983.

${ }^{69}$ Anexo C, Acta 269, 4/8/1983.

${ }^{70}$ ECI, Proyecto de Ley, Anexo B, p. 16, Acta 274, 8/9/1983. 
denuncias del "personal propio condenado que no se verá beneficiado con la ley". Asimismo, la decisión de incluir la cláusula de revisión presidencial ilumina el hecho de porqué se revisó la lista de condenados militares que mencionamos más arriba bajo la idea de que eran "potenciales denunciantes" y se evaluara para cada uno la posibilidad del indulto o la conmutación de la pena. Pero esas mismas listas muestran que, a pesar de lo que las autoridades militares públicamente decían respecto de que había 150 miembros de fuerzas de seguridad detenidos en cárceles comunes, en realidad la mayoría no lo estaban por delitos vinculados a operaciones represivas y/o no tenían sentencia firme. Por lo tanto, aunque los militares afectados por esta restricción de la ley eran pocos, para ellos se incluyó la cláusula de la posibilidad de indulto y/o conmutación de pena por decisión especifica del Ejecutivo. Esto permitía distinguir, en la práctica, entre militares y subversivos allí donde la norma aparentemente los igualaba en sus beneficios.

Como concluye el informe solicitado por la Junta para evaluar esos posibles mecanismos restrictivos: "las exclusiones afectan primordialmente a un sector -terroristas y subversivos-“."71 El mismo informe agregaba que esas limitaciones comprometían el principio de generalidad que debía tener toda amnistía. Por lo tanto, aunque no se dice, es evidente que la decisión de incluir ambas restricciones ponía directamente en riesgo la viabilidad jurídica de la ley -aspecto que, como vimos, era clave en las preocupaciones militares- y había sido objeto de muchas consultas.

La cuestión interesante es que con estas restricciones incluidas en la redacción final, la Junta aceptó a correr riesgos en sus dos mayores desvelos: la eventual ruptura de la cohesión interna por denuncias de miembros de la propia fuerza no incluidos en la amnistía y la vulnerabilidad jurídica de la ley frente al poder judicial y el nuevo congreso democrático. Pero, seguramente, de no haberse incluido esas limitaciones, la ley no hubiera sido tolerada por las propias fuerzas, y de no aprobarse la ley los militares pensaban, como dice uno de los documentos, que: "se producirá indefectiblemente la revisión de lo actuado durante la lucha antisubversiva". ${ }^{72}$

\section{Reflexiones finales}

El 23 de septiembre de 1983, la Comisión de Asesoramiento Legal (CAL) -órgano que oficiaba como ámbito legislativo y de consulta para el gobierno militar- promulgó la ley considerando que era de "significativa trascendencia" y, por tanto, debía ser aprobada tal cual había sido enviada por la Junta y sin revisiones. ${ }^{73}$ En su artículo principal la ley establecía:

“Art. 1. Decláranse extinguidas las acciones penales emergentes de los delitos cometidos con motivación o finalidad terrorista o subversiva, desde el 25 de mayo de 1973 hasta el 17 de junio de 1982. Los beneficios otorgados por esta ley se extienden, asimismo, a todos los hechos de naturaleza penal realizados en ocasión o con motivo del desarrollo de acciones dirigidas a prevenir, conjurar o poner fin a las referidas actividades terroristas o subversivas, cualquiera hubiere sido su naturaleza o el bien jurídico lesionado. Los efectos de esta ley alcanzan a los autores, partícipes, instigadores, cómplices o encubridores y comprende a los delitos comunes conexos y a los delitos militares -+conexos."

Se ha insistido siempre -y nuestro trabajo también lo confirma- en la oposición generalizada de los principales actores de la escena pública a la amnistía. Sin embargo, el examen del proceso interno que llevó a su aprobación muestra que esa oposición -civil, y partidaria en particular- no

\footnotetext{
${ }^{71}$ ECI, Anexo 2, p. 16, Acta 274, 8/9/1983.

72 ECI, Anexo A, p. 6, Acta 270, 18/8/1983.

73 D-CAL 583/1983. Archivos de la Comisión de Asesoramiento Legal, en el Archivo Intermedio del Archivo General de la Nación.

${ }^{74}$ Ley 22.924, 22/9/1983.
} 
se manifestó $-\mathrm{O}$ al menos no fue percibida- como un obstáculo para la sanción de la ley. Como señalan Marcos Novaro y Vicente Palermo, los militares no tenían mucho para negociar ni concesiones para ofrecer a los partidos políticos a cambio de la ley, pues no había cuerpos que entregar, ni grandes contingentes de presos para liberar ni exiliados para permitir su regreso, y eso llevó a la oposición partidaria a no flexibilizar su oposición a la ley. ${ }^{75} \mathrm{Si}$ bien este análisis resulta adecuado, parecería que la oposición partidaria, lanzada como estaba a la arena electoral, tampoco intentó constituirse en una presión con la que la Junta necesitara negociar algo real -al menos según se desprende de la documentación analizada-. Por ejemplo, los partidos no exigieron información sobre los desaparecidos -que era la principal demanda de época en la coyuntura del fin de la dictadura-, ni la liberación de los presos políticos ni el regreso de los exiliados cualquiera fuera su número- a cambio de alguna forma de negociación sobre la amnistía. También es cierto que esto se daba en un momento donde los militares ya habían indicado su voluntad de no dar más información a partir del "Documento final..." dado a conocer meses antes de la ley de autoamnistía. De esta óptica, la falta de presión de la oposición partidaria también podría estar vinculada a la dinámica de las (no) negociaciones con que se estaba dando, en general, el proceso de salida y a la prioridad de los partidos colocada en llegar a las elecciones del 30 de octubre.

En todo caso, los partidos políticos ya venían obteniendo desde un año atrás las concesiones de mayor interés para ellos, vinculadas a la normalización institucional y partidaria. Y si bien es cierto que la Multipartidaria se había negado a "concertar" con la Junta Militar en un duro documento en diciembre de 1982, también es cierto que en ese documento el único punto menos tajante era la cuestión de los desaparecidos sobre los cuales solo se pedía una respuesta "franca" ${ }^{76}$ Por lo tanto, otra variable a considerar es que la oposición partidaria a la ley haya estado más basada en una posición antidictatorial general, propia de la coyuntura de colapso del régimen -que para algunos de esos sectores incluía no dejar pasar los "excesos" y "errores" de la represión-, que en una real oposición a la represión y a la lucha antisubversiva como hechos criminales globales. En cualquier caso eso deberá ser objeto de nuevas y específicas investigaciones. ${ }^{77}$

En cambio, parecería que las características de la ley de autoamnistía estuvieron más bien definidas por los imperativos de la negociación intramilitar y la desesperación por protegerse judicialmente en ese mismo momento y bajo el futuro régimen. Por tomar un ejemplo claro, tal como hemos visto, la discusión sobre si se liberaba o no a los subversivos que llevó larguísimas deliberaciones no fue una cuestión de la cual dependiera algún cambio en la aceptación civil de la amnistía -poco podían estar de acuerdo los partidos políticos protagonistas de la transición con la liberación de los terroristas de antaño por cuya represión todos habían aceptado la lucha antisubversiva y cuyo regreso al país muchos veían como un riesgo para la democracia, incluso dentro del propio peronismo-. En cambio, la negociación sobre esas liberaciones fue intramilitar y estuvo jaqueada por la necesidad de reducir los beneficios para esos grupos y obtener, a cambio, la aceptación de la ley por parte de la Marina y sectores duros del Ejército.

Así, la coyuntura de la gestación de la ley muestra, una vez, más el elevadísimo nivel de conflicto y la manera extrema de resolverlo -a través de la capacidad de veto y la crítica feroz, y, también,

\footnotetext{
${ }^{75}$ Novaro, Marcos y Palermo, Vicente, La dictadura militar..., op. cit., p. 509.

${ }^{76}$ Quiroga, Hugo, El tiempo del proceso..., op. cit., p. 336.

77 Desde luego cualquier asunción sobre las posiciones partidarias exigiría discriminar entre partidos y líneas distintas dentro de cada fuerza, lo cual excede las posibilidades de este texto. Las líneas aquí consagradas a los partidos los consideran como actor conjunto en relación con las Fuerzas Armadas y pretenden indicar problemas a pensar más que resolverlos.
} 
del papel moderador o intermedio de la Fuerza Aérea ${ }^{78}$ - que caracterizó a la última dictadura militar. Además, los conflictos específicos planteados en la interna militar dejan en evidencia que el obstáculo interno para la ley no era otro que el peso de la profunda convicción ideológica y del espíritu de cruzada con que se llevó adelante la represión en la Argentina. En definitiva, más allá de las históricas diferencias inter e intrafuerzas y su álgida historia de siete años en el ejercicio del poder, el proyecto de amnistía ponía en cuestión aquella única convicción que les había permitido resistir cohesionados a todas las otras diferencias y que había sido el sustento fundamental del régimen: la lucha antisubversiva. ${ }^{79}$ Como denunciaba la Marina, la autoamnistía los igualaba con sus enemigos y lejos de reconocer su carácter de salvadores de la patria implicaba, finalmente, el reconocimiento de que "algo habían hecho".

Escasos dos meses después, el 22 de diciembre, la ley fue anulada por nulidad insanable por el nuevo régimen democrático. Los fundamentos de la decisión, según el proyecto presidencial enviado al congreso, fueron los siguientes: desde el punto de vista ético, las "más elementales exigencia de justicia" requerían un "castigo ejemplificador" por hechos que "desconocían de la manera más brutal y completa la dignidad de la persona humana". Desde el punto de vista político, el mantenimiento de la ley hubiera implicado extender responsabilidades de manera indiscriminada sobre la institución militar cuando debería "recaer en diferentes grados sobre algunos de sus hombres" y porque "la posibilidad de investigar y castigar los hechos es esencial para que los órganos constitucionales tengan en el futuro el control absoluto del monopolio de la fuerza". Desde el punto de vista jurídico, porque la ley violaba el principio de igualdad ante la ley y beneficiaba a los propios miembros del gobierno; porque era de nulidad insanable todo acto que implicara arrogarse la suma del poder público, porque la doctrina de los gobiernos de facto tenía una validez precaria o perdía esa validez si eran injusta como en este caso, y porque esos vicios jurídicos hacían que la ley de Pacificación fuera insanablemente nula y, por tanto, el principio de la ley penal más benigna era inaplicable. ${ }^{80}$

Cuando la Junta Militar y sus asesores pensaron a lo largo de 1983 que la amnistía no corría riesgos, se equivocaron. Inscribieron el análisis de su viabilidad en la tradición jurídica y constitucional previa que, por sobre todo, había tendido a respetar la doctrina de facto. Probablemente lo que las Fuerzas Armadas no terminaron de percibir en 1983 era hasta qué punto el Proceso de Reorganización Nacional y sus crímenes estaban fuera de las tradiciones previas, fueran militares, civiles, políticas o jurídicas. A su vez, ni ellos ni otros actores de la época esperaban que el radicalismo fuera la fuerza triunfante el 30 de octubre. Y la voluntad alfonsinista, por razones más complejas que el mero deseo de justicia, y respaldada abrumadoramente por las dos cámaras parlamentarias, también fue disruptora de toda tradición jurídica y política. Y más allá de sus límites $-\mathrm{y}$ de que mucho de lo que sucedió fueron derivas no planificadas ni elegidas por la gestión radical-, terminó creando escenarios de justicia innovadores como no pudo hacerlo ningún otro país de la región.

\footnotetext{
${ }_{78}$ Canelo, Paula, El proceso en su laberinto..., op. cit.

${ }^{79}$ Sobre la importancia de las diferencias militares, sus formas y variaciones, a lo largo del PRN, véase Canelo, Paula, Elproceso en su laberinto..., op. cit.

80 Proyecto de Ley de derogación de la Ley 22.924, Cámara de Diputados de la Nación, 16 de diciembre de 1983, Anales de la Legislación Argentina. Sobre la anulación de la ley y el contexto en el cual se produjo, véase Franco, Marina, "La teoría de los dos demonios.", en Feld, Claudia y Franco, Marina (eds.), Democracia hora cero, Actores, prácticas y debates en la primera posdictadura, Buenos Aires, en prensa.
} 